\title{
Employer Expectations for Graduates from Haiti's Agricultural Universities
}

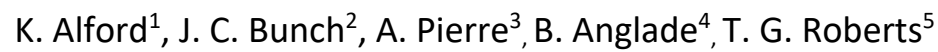

\section{Abstract}

Human capacity building in Haiti's agricultural sector can be utilized to reduce the country's food insecurity. Haitian agricultural university and technical schools are responsible for supplying workforce ready graduates and therefore play a role in poverty reduction. Previous research has been conducted to assess these institutions from the perspective of faculty, students, and farmers. However, the employer perspective has not been considered, which could lead to a disconnect between what employers and the university believe are essential skills for graduates to obtain. This study focused on identifying the perceptions of the Haitian agricultural workforce regarding the ability of technical schools to produce graduates. This study used a basic qualitative design involving interviews of Haitian agricultural employers. The interviews revealed employers perceptive of curriculum strengths and weaknesses as well as desired employer skills for graduates. Employers also provided insight into the current job opportunities for graduates as well as what makes an "ideal" employee. We found a disconnect between jobs available and the skills being taught to graduates to fill these jobs. While employers desire employees with strong soft skills, there is a need for more technical skills to be taught at the agricultural schools.

\section{Keywords}

Haiti, TVET schools, universities, capacity building, employer perception, curriculum reform

1. Katrina R. Alford, Graduate Student, University of Florida, 305 Rolfs Hall PO Box 110540 Gainesville, FL 32611, trini@ufl.edu, https://orcid.org/0000-0002-2769-1388

2. J.C. Bunch, Associate Professor, University of Florida, 307A Rolfs Hall Gainesville, FL 32611, bunchj@ufl.edu, https://orcid.org/0000-0001-8729-2349

3. Absalon Pierre, Post Graduate Coordinator for Université Internationale D'Hispaniola-UNIDHI, AREA PROJECT-Haiti, University of Florida, 12 rue St-Patrick, Delmas 33, Port-au-Prince, Haiti, absulpeter@yahoo.fr, https://orcid.org/00000003-0688-3409

4. Boaz Anglade, Post-Doc Researcher, University of Florida, P.O. Box 110180, Gainesville, FL 32611 banglade@ufl.edu, https://orcid.org/0000-0002-7436-4056

5. T. Grady Roberts, Professor, University of Florida, 117C Bryant Hall PO Box 112060, Gainesville, FL 32611, groberts@ufl.edu, https://orcid.org/0000-0001-7618-7850 


\section{Introduction and Problem Statement}

A succession of shocks from natural disasters, structural weaknesses and political turmoil have severely impacted Haiti, resulting in an increasingly vulnerable population (FAO, 2019). It is estimated that almost 3.7 million people are in urgent need of action due to acute food insecurity, which is predicted to worsen (Food and Agricultural Organization (FAO), 2019; FAO \& World Food Programme (WFP), 2020). As a result, the government of Haiti issued an action plan that focused on having agriculture be the driving factor in economic recovery (Government of Haiti (GoH), 2010). According to David and Samuel (2014), the development of the agricultural sector cannot occur unless there is an effective extension system.

Haiti will need to strengthen research, education, agricultural services, and institutions of the Ministry of Agriculture (Goertz, 2016). The extension services within Haiti need to be strengthened, since they link agricultural productivity to agricultural education using extension agents (Calixte, 2018). Extension services are important because they not only disseminate research to farmers but also communicate the needs of specialists and farmers to the researchers (Anaeto et. al, 2012). A review of extension services in South Africa determined that a "linear approach to development of agriculture innovation should be discouraged" (p. 92), because it leaves out the opinions of stakeholders and farmers (David \& Samuel, 2014).

According to Mouzakitis (2010), improvements of vocational education and training should be based on needs assessment research. Research has been ongoing about the state of Haiti's multiple agricultural institutions including Technical and Vocational Education and Training (TVET), Agricultural Universities and Extension Services from the perspective of faculty, farmers, and students (Albert et al, 2017; Calixte et al., 2019a.; Calixte et al., 2019b; Pierre et al., 2018) however, the employer's perspective has not been fully explored. Calixte et al. (2019b) recommended determining the skills and competencies employers desire for graduates, and Pierre et al. (2018) stated perspectives should be triangulated to provide a more complete picture of student preparedness.

\section{Theoretical and Conceptual Framework}

Capacity is defined as "the ability of people, organizations and society to manage their affairs" (OECD, 2012, p. 7), and this process must be initiated from the inside, by the people themselves. Capacity development in turn focuses on the process of unlocking this capacity through various strategies, structures, resources, and relationships among the various actors (Baser \& Morgan, 2008). Capacity development projects focus on multi-stakeholder engagement, in which an understanding of the context is needed to build dynamic relationships among stakeholders (Ika \& Donnelly, 2017). Feedback from the environment is critical so that those in charge of the development of the system can revise their approaches based on the information they received (Elliot, 1989). In the context of Haiti, employer feedback is necessary for TVET schools to be able to gain valuable stakeholder knowledge on the best way to improve their programs (i.e., curriculum) as well as their graduates (i.e., the workforce), and 
increase capacity among both. As capacity increases so does the ability for the system to increase economic growth, food security, and poverty reduction (Gill et al., 2017).

According to Yilmaz (2008), social constructivism operates on the premise that knowledge is socially constructed. Humans' understanding of the world is shaped through social context and social negotiations (Hwang, 1996). Rivera-Ferre et al. (2013) argued that agriculture is a complex socio-ecological system that must consider the human-human interactions within the system. Framing, the set of assumptions an individual holds, is important for navigating their mental map of a particular issue (Bolman \& Deal, 2013). Framing involves subjective perspectives, and as such, any study involving an agricultural system depends on understanding the narratives used within the system (Rivera-Ferre et. al., 2003). The interactions between the agricultural institutions, faculty, graduates, and employers are influenced by the frames each hold regarding the agricultural system. Participation in decision making can bridge and/or change mental maps, therefore increasing capacity (Rivera-Ferre et. al., 2003).

A systems thinking approach should be utilized to examine the interactions of entities to look at the whole picture and find interrelated parts (Senge, 1990). Systems thinking is focused on looking at the relationships and patterns of interdependent components of a system through a non-linear perspective (Leischow \& Milstein 2006). Previously agricultural development efforts utilized a linear approach to problem solving, but a shift to holistic systems approach that focuses on interconnectedness between components of the agricultural sector is needed (Banson et al., 2016). The United Nations Educational, Scientific and Cultural Organization (UNESCO) acknowledge that TVETs have a reciprocal relationship to changes due to globalization, technology, policy, and so forth, and their TVET strategy includes utilizing a holistic approach to adapt to change (UNESCO, 2015). Within this context of systems and relationships, the Agricultural Innovation System (AIS) provides the framework for Universities to work with employers to rebuild the Extension service (TAP, 2016).

The AIS can be divided into four components (a) research and education, (b) bridging institutions, (c) business and enterprise, and (d) the enabling environment (Hall et al., 2006). The components form a network of actors who work together to bring about agricultural innovations (TAP, 2016). Figure 1 provides a visual of the AIS system and the linkages between research education and business and enterprise. Employers should be involved in the development of curriculum since they have an understanding of what skills and competencies graduates need (Kraak et al., 2016). Within the Haitian TVET system, it is has been found that employer insight is lacking regarding curricular development, which can affect the employability of graduates (Calixte et al., 2019b). 


\section{Figure 1}

Conceptual diagram of an Agricultural Innovation System

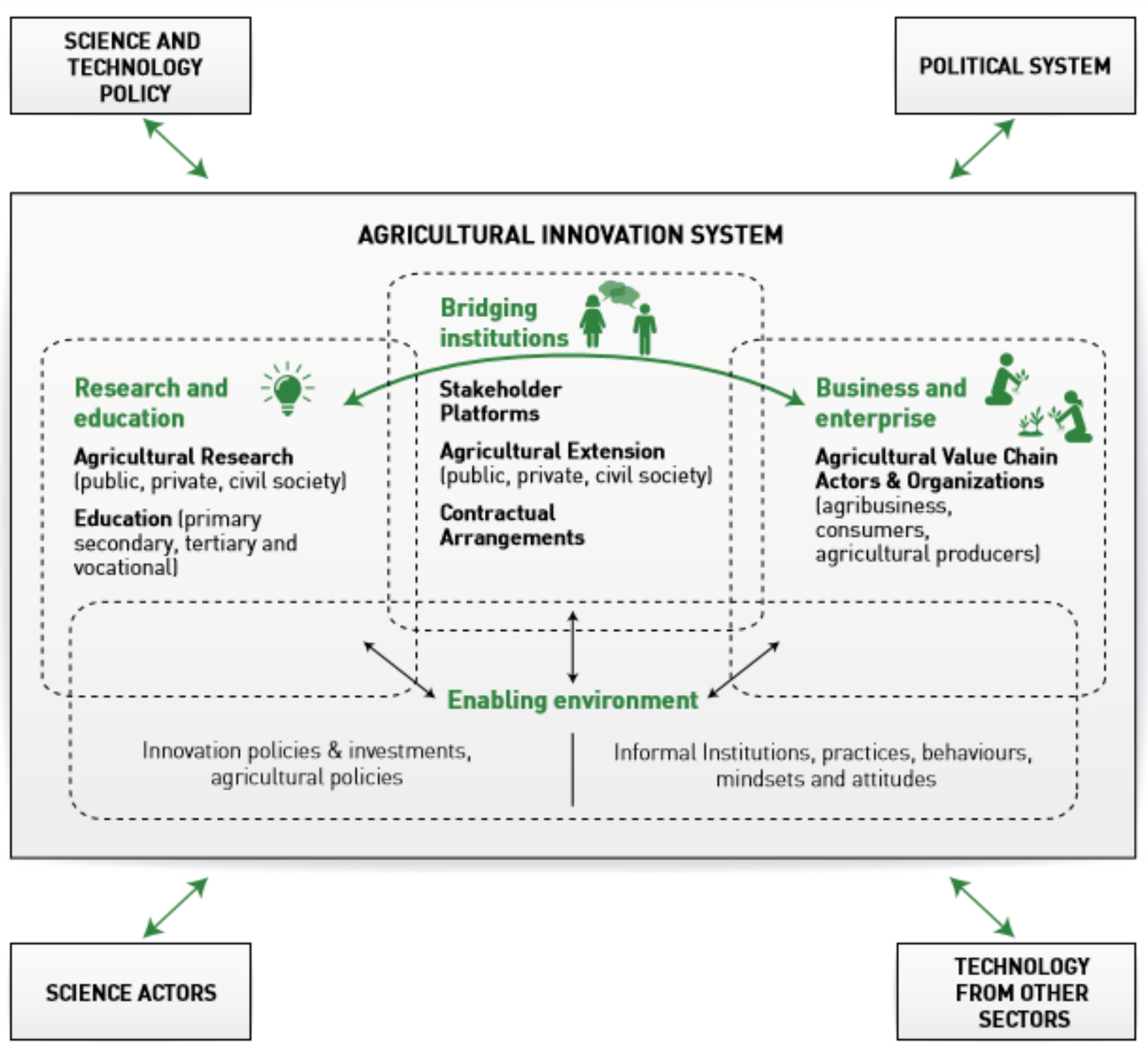

\section{Purpose}

This study was part of a larger study funded by USAID focused on examining the ability of Haitian agricultural universities to supply work-ready graduates. Previous research examined this from the perspective of university faculty (Pierre et al., 2018), and considered employment opportunities of graduates (Calixte et al., 2019b). This study focused on identifying Haitian 
employers' perception of graduates and curriculum. Four research questions guided the inquiry:

1. What are the employment opportunities for recent graduates?

2. What is the ideal employee?

3. What are employers' desired skills and competencies for new employees?

4. What are employers' perceptions of the university curriculum?

\section{Methods}

This study employed a basic qualitative design (Flick, 2007) using a social constructivist lens. Interviews were conducted with 17 Haitian agricultural employers using a semi-structured interview guide with 22 open-ended questions. The interview guide was developed based on the literature and a panel of experts familiar with the context. This panel included Haitian and Haitian American researchers as well as Americans with previous research experience in Haiti.

The target population for this study was Haitian agricultural employers. The sample was composed of 17 employers who were involved in all types of work in Haiti. The individual participants involved in this study were mostly Directors and Assistant Directors in their respected companies (P001, P002, P005, P006, P008, P009, P010, P013, P015, and P016). The remaining individuals held the offices of Coordinator, or Vice President/rector (P003, P004, P007, P011, P012, P014, and P017). Each of the individuals identified that they had been employed for many years in these roles. Job duties ranged from financial (P001, P010, P011, P012, P013), promotion efforts (P002, P003, P007), research (P06, P09), and supervision of specific programs (P04, P08, P014, P015, P016). Participants self-identified as working in extension $(n=4)$, research $(n=4)$, general agriculture $(n=9)$, social programs $(n=3)$, agroindustry $(n=3)$, environmental protection $(n=2)$ and sustainable agriculture $(n=2)$. Employers may have identified their work as falling into multiple categories. The number of employees each employer hired varied. The number of employees ranged from 10 to 120 at any given time. In addition to full time employees, one employer (P003) identified having employed 70 interns. Female employment ranged from $0 \%$ to $40 \%$ among the employers involved in this study, although employers did state they attempted to hire equally among males and females.

Data were collected using face-to-face interviews at the employer site. The interviews conducted with the employers lasted one to two hours. Interviews were conducted in French and Creole by a Haitian researcher and translated to English later. In addition to the researcher, a research assistant was present. The researcher and research assistant took detailed notes during each interview. Following each employer interview, the research team created a detailed case file for each individual employer, which included transcripts, interview summary, and notes. Once the detailed case file was completed, the research assistant verified the accuracy of each case file. At the completion of the verification process, results were presented at meetings and conferences to participants as a form of member checking (Merriam, 1998). Their feedback enriched the data by providing further details and confirmed other conclusions. 
Data were analyzed using a basic thematic analysis using line-by-line coding (Gibbs, 2007). The first round of coding led to initial codes which were then organized into themes. To establish dependability (Lincoln \& Guba, 1985) in the analysis, two researchers collaborated on the initial analysis. A Haitian researcher analyzed 17 case files in French and an American researcher analyzed the same 17 case files translated to English. Analyses were compared after each case file was analyzed and the researchers collaborated to refine coding techniques.

\section{Findings}

\section{Employment Opportunities for graduates}

Three themes emerged from the data regarding employment opportunities for recent graduates: not enough jobs, relationships between employers and university/TVET partnerships in securing a job, and expectations from employers regarding field versus management jobs.

\section{Not Enough Jobs for Recent Graduates}

There is a high degree of unemployment in Haiti which has resulted in a few job opportunities for graduates. Employer recruitment efforts reflect the external environment of there being more people than jobs. Employers do not have to spend much time recruiting because workers are taking the initiative to apply for limited jobs and/or employers use their social contacts to fill positions.

High unemployment. Employers are faced with the situation where there are more applicants than job openings. P002 stated "I cannot hire all people who seek employment due to the lack of funds." This is echoed by P012 who stated, "I will not have enough employment for the quantity of people who will apply." P16 stated that when they recruited online, they were shocked by the number of applicants but that this was an indication of the high level of unemployment. The hiring process is highly competitive (P001) because of the scarcity of jobs.

Recruitment. A common thread among employers was that they did not have to recruit much to fill positions. P002 mentioned that they did not even have to advertise to fill positions. P001 stated that others bring their resumes to the company who then follow up if they meet the job requirements. P004 mentioned that they only recruit if there is a special project, but often people would bring them their resumes. If employers recruit workers, they utilize the following calls in Le Nouvelliste (a national newspaper), online recruitment tools such as JobPaw, and social contacts such as contacting professionals or universities for recommendations.

\section{University Partnerships}

Several employers mentioned that they partner with schools in internships which led to job offers. According to P008, recruitment was done through a program or a process of selection during the internship program offered to fourth year students. After this internship, some are hired and some benefit from scholarship programs. P003 had a similar program at his institution, where they directly contacted the Deans to recruit interns. P003 explained that when starting a new project, they would recruit at academic institutions based on the theme of 
the project. P013 recruited among previous intern students from different colleges who had some prior experiences with his company. At P014's institution, recruitment of new agronomists depended on the department and colleges. Although P009 did not directly recruit new employees, he did say that he had great contacts with the universities.

\section{Employers Perception of Field Versus Management Jobs}

Employers appear to prefer hiring recent graduates into technician and field agent roles. P013's company offered employments as technician and experimental farm agent. P001 reported he recruited young (new graduates) agronomists to work in water management and area management. Those who were employed in area management worked closely with farmers. He described these area managers as technicians filling an extension role. P12 hired both engineer-agronomists and technicians but the last group is the largest since they are more practical than the first group. P006 explained that job opportunities were more evident in the field, like at the technical school of agriculture, than at the managerial level. He elaborated that managerial level jobs required someone experienced with autonomy and responsibility which was not suited for a recent graduate. At the management level, he believed these positions were for the professional and more experienced individuals. For example, one of the vacancies at his unit was in monitoring and evaluation. For him, this required someone with lots of experience, and not a new graduate. However, a young graduate might be hired to support a person in this role to gain experience.

\section{The Ideal Employee- Desired Skills and Competencies}

Employers consider their ideal employer to be well rounded and having both personal competencies, key transferable skills, as well as necessary qualifications to complete their job.

\section{Personal Competencies}

Employee motivation and work ethic were mentioned by several employers as being important for an ideal employee. P001 valued an employee who displayed a strong work ethic. He would be more likely to give a job to a less experienced employee if they demonstrated a strong work ethic. P008 desired graduates with the competency of punctuality. P002 was not satisfied with his current agronomist because of the employee's lack of motivation. As such, he seeks an employee who possesses internal motivation to complete job tasks. P004 related that at their company they so not do babysitting and their employees must be proactive and willing to work. Between two interns that were hired, the individual with the higher GPA was not as valued as the individual who was proactive.

Key transferable skills. Adaptability to change was a skill highly valued by employers. P003 explained that in many cases the job description may change from the original time of hire, so it was important that employee be able to adapt. This was also stated by P001 who felt that one of the most important competencies to hold were one's ability to adapt to change. P009 favored employees who display an entrepreneurial spirit and were open-minded to solve problems. P004 wanted an employee who is bilingual. She explained that the ability to speak another language like English or Spanish was good for the employee and company. Additionally, P003 valued an employee with strong communication skills, critical thinking ability, and leadership skills. P012's ideal employee has the ability to work in a team setting. He 
desired employees who understood team dynamics and can function well in a team. P008 also mentioned that he desired employees who were competent in teamwork.

\section{Job Qualifications}

To be successful, P001 felt that employees needed to be competent in adult learning and agricultural entrepreneurship. P006 wanted to see graduates who had strong competencies in the areas of extension and research. P016 felt that key transferable skills such as teamwork and being adaptable were important job qualifications. In contrast P012 and P015 were more concerned with the technical competency of the student then most. They did not think the other competencies were as important as the technical ability of the employee. P004 also desired employees who understood the faming system.

P010 and P011 both exclaimed that graduates with the competency to deliver educational programs and evaluate those programs would be highly effective. P014 also wanted graduates who could deliver training programs and work in a team environment. P006 focused on evaluation as being necessary for success but stressed that this competency could not be built without experience. He thought that students who have the capacity to evaluate programs would be highly desired in the field. P017 thought all competencies were important, however, employees who displayed strong competencies in gender issues in agriculture and program planning were most desired.

\section{Current Curriculum Strengths and Weaknesses Strengths}

The primary theme that emerged from the employers was that the current curriculum prepares students theoretically for their work. P006 stated that the theoretical content was very rigid, and students were really good in theory and had access to a lot of information due to the internet. P013 supported this notion by exclaiming that students were really excellent in learning theory and memorization. P015 also spoke about how Haitian colleges of agriculture curriculum offered a solid theory base for graduates that allowed students to pursue postgraduate studies abroad without any problem. Students could take the theory taught and apply it to their current work context (P003). Aside from being strong theoretically, P001 thought that the inclusion of general education courses was a strength, because they helped develop a holistic graduate. He further explained that these courses helped graduates take opportunities.

\section{Weakness}

Employers highlighted several weaknesses of the curriculum, but the primary weakness was the lack of practicums to go with the strong theoretical base. Employers felt that both the curriculum and the structure of the schools were contributing to this weakness.

Lack of practical experience within the curriculum. P008 said the program of study needed to be adapted to the reality of production to produce competent professionals in the field. He advocated the entire curriculum be changed because the curriculum did not reflect the actual needs to the country. He felt that focusing the curriculum more on production would give students more opportunity for practice. P002 echoed this by saying that the curriculum 
was not complete because graduates did not have the capacity to solve practical problems. He lamented that the lack of practice was a problem and caused many graduates to be incompetent in the field. P010 and P014 both complained about the lack of practice in graduate curriculum in Haiti. In addition, P013 deplored that students were really good in memorization and theoretically knew the content but lacked practical experience.

Structural issues contributing to the curricular weakness. P002 felt that the absence of laboratories was to blame for the lack of practical experience. Students are unable to gain and/or practice practical skills because of the shortage of laboratories. P007 talked about the poor infrastructure at the university, and he felt that if infrastructure were improved this would allow for better quality laboratories for students to gain skills. P009 supported this notion by simply saying laboratories were not in functioning operation. Although P009 did not reference the type of laboratories, he was most likely referring to both science type laboratories and practical field type laboratories. P007, P008, P010, P011, and P014 all made the case that due to lack of infrastructure students were unable to practice skills and technology. As an example, P017 explained that when they did a soil test or a $\mathrm{pH}$ to analyze the soil, there were no ways to see the results. The lack of practical skills in the curriculum is tied to the lack of resources students have in obtaining these practical skills.

\section{Curriculum Improvement}

When thinking about curriculum improvement, several of the participants had recommendations in this area. These recommendations focused on acquisition of practical skills for graduates and faculty development.

\section{Acquisition of Practical Skills}

Employers felt that the disconnect between content taught at the schools and the reality in the field needed to be addressed. P001 and P016 said the curriculum should focus on "real" needs of the market and country. The curriculum did not correspond to the market needs. In fact, P017 said that the curriculum of the colleges of agriculture did not address $50 \%$ of the market need. This involves the curriculum focusing more on practice and less on theory (P008, P011). P001 recommended more emphasis be put on time for practice and entrepreneurship theory and skills.

Desired Practical Skills. Although participants mentioned that students lacked practical agriculture skills, very few employers mentioned specific practical agricultural skills they desired to see. Two participants did provide some examples, P016 stated that students should have skills in soil and arboriculture and P10 said that new agronomists needed to have experience with the environment. Many employers though focused on non-agriculturally related skills such as software knowledge and skills. P002, felt that new graduates should be emerged in curriculum that is focused on computer technologies both hardware and software. P009 would like to see students' study and master specific programs such as Word, Excel, and statistical software. Along with including software in the curriculum, P008 insisted that the curriculum include writing and presentation practices to increase students' ability to communicate effectively. Additionally, P008 and P014 explained that the curriculum should teach students to use research results and make decisions. In fact, P016 supports this notion by stating students should know how to analyze data using software. 
Infrastructure Changes. To address the need for more practical skill acquisition institutions needed to invest in more laboratories and resources. P011 said that agricultural sciences could not be thought inside four walls. Moreover, P002 mentioned emphasis should be put on building practice fields and laboratories to allow students to develop practical skills. P004 stated that institutions should have more labs with adequate laboratory kits and materials.

\section{Faculty Development}

Employers stated that curriculum improvements need to consider faculty development. P017 said that faculty could not continue to use tchala (an old copy or notes book). P004, P015, and P017 all recommended professional development programs for faculty regarding teaching methods. Specifically, P004 stated, professors should know and understand the art and science of teaching. P003 was concerned about the teaching methods used by faculty, with the implication that faculty must understand and use different methods

\section{Conclusions, Discussion, and Recommendations}

Employers state that high unemployment is an issue for new graduates seeking jobs with supply far outstripping demand. However, partnerships between the employers and educational institutions have produced jobs for graduates. Internships primarily are the method that employers use to recruit directly from the schools. It is recommended that the agricultural schools invest in developing more internship programs with various agribusinesses. In addition, research should be conducted to determine the prevalence and strength of existing partnerships.

Employers view management level positions as being for those with more experience and are not a new graduate position and prefer for new graduates to take technician and field agent roles. This employer mindset should be taken into consideration by Haitian agricultural schools so that they can adequately determine which areas of the curriculum should be modified. If field positions are what is mostly available for new graduates, the curriculum may want to emphasize the more practical skills so graduates can be ready for the available jobs. This is in line with employers who said that technical competencies and practical experiences are both desired. However, employers did not provide specific agricultural skills they expected graduates to be competent in and further investigation should occur in order to make appropriate curricular modifications.

The employers in this study support this argument that soft skills and personal competencies are equally as important as the technical skills. Mcquaid and Lindsay (2005) stated that individual factors are important to holistically assess an individual's employability. Baser and Morgan (2008) argued Haitian employers are looking for schools to increase organizational development which focuses "human and organisational qualities such as resourcefulness, identity, resilience, innovation, collaboration, adaptiveness, courage, imagination and aspiration" (p. 52). According to Mcquaid and Lindsay (2005) personal competencies focus on 
attributes such as self-motivation, initiative, and proactivity while key transferable skills involve adaptability, communication skills, teamwork and problem solving. TVET schools are recognizing that their graduates will encounter many types of jobs and are trying to prepare their graduates to be versatile (Calixte et al., 2019b) and employers supported their efforts for the inclusion of soft skills. Research should be conducted to determine if universities and TVET schools are deliberately teaching soft skills and graduate's efficacy in these soft skill areas.

In keeping with systems thinking, this static image of desirability of soft skills in employees does not demonstrate the whole picture of graduate preparedness. Employers view the curriculum as being very strong theoretically but lacking in practical aspects, which is apparent when employers describe their employees not receiving much practical technical training. With many of the opportunities for recent graduates focused on field work, the need for the curriculum to focus on these practical opportunities is evident. Employers mention the lack of field experience inhibits student success which is supported by Calixte et al. (2019c) who found the lack of resources made it difficult to implement practical experiences. It is recommended that the schools invest in labs and field equipment to ensure graduates receive practical experience.

Employers note that faculty need professional development to assist them with teaching methods. Looking holistically at the curriculum, employers recognize faculty need proper teaching strategies when designing the curriculum to meet their students' needs. Riebe et al. (2016) state that to deliver desired learning experiences, an understanding of curriculum design and teaching strategies is necessary. It is recommended that professional development should be conducted to ensure faculty are prepared to meet graduates needs.

Universities and TVET schools should continue to teach theoretical knowledge, with an emphasis on soft skills to students. However, incorporation of soft skills into the curriculum should not come at the expense of technical/practical skill development of the graduates. As such, capacity needs to be developed across all dimensions so that graduates can interact with all parts of the system in which they are working within (Gill et al, 2017). Should these recommendations be implemented, further research should be conducted to determine if employers notice a change in recent graduate preparedness. Ika and Donnelly (2017) stated that the relationship between stakeholders is important for capacity development, Thus, Haitian universities and TVET schools need to address employers' needs for both soft skills and practical experiences so that graduates can become effective bridging institutions between stakeholders (TAP, 2016). Lastly, research is needed to gain a better understanding of additional external factors which affect graduates' abilities to act as bridging institutions from the employer's perspective. 


\section{Acknowledgements}

This study is made possible by the generous support of the American people through the United States Agency for International Development (USAID) under the cooperative agreement \# AID-OAA-A-15-00039. The contents are the responsibility of the authors and do not necessarily reflect the views of USAID or the United States Government.

\section{References}

Anaeto, F.C., Asiabaka, C.C., NnadiF., N., AjaeroJ., O., Ajao, O., \& UgwokeF., O. (2012). The role of extension officers and extension services in the development of agriculture in Nigeria. Wudpecker Journal of Agricultural Research, 1(6), 180-185.

Albert, B., Roberts, T. G., \& Harder, A. (2017). Career development influences of employees working in Haiti's agricultural extension and advisory services. Journal of International Agricultural and Extension Education, 24(2), 107-121. https://doi.org/10.5191/jiaee.2017.24208

Banson, K. E., Nguyen, N. C., \& Bosch, O. J. H. (2016). A Systems Thinking Approach to the Structure, Conduct and Performance of the Agricultural Sector in Ghana. Systems Research and Behavioral Science, 35(1), 39-57. https://doi.org/10.1002/sres.2437

Baser, H., \& Morgan, P. (2008). Capacity, change and performance (Discussion Paper No. 59B). European Centre for Development Policy Management.

Bolman, L. G., \& Deal, T. E. (2013). Reframing organizations: Artistry, choice, and leadership. John Wiley \& Sons.

Calixte, M. C. (2018). Understanding Haitian agricultural technical and vocational education and training: Review of four schools [Unpublished master's thesis]. University of Florida.

Calixte, M. C., Roberts, T. G., \& Bunch, J. C. (2019a). Exploring the purpose of agricultural technical schools in Haiti. Journal of International Agricultural and Extension Education, 26(2), 121-137. https://doi.org/10.5191/jiaee.2019.26209

Calixte, M. C., Roberts, T. G., \& Bunch, J. C. (2019b). Employment opportunities for graduates of agricultural TVET schools in Haiti. Journal of International Agricultural and Extension Education, 26(3), 43-57. https://doi.org/10.5191/jiaee.2019.26303

Calixte, M. C., Roberts, T. G., \& Bunch, J. C. (2019c) The balance of theoretical and practical skills in agricultural technical schools in Haiti: An exploration of the curriculum. Journal of International Agricultural and Extension Education, 26(2), 14-28. https://doi.org/10.5191/jiaee.2019.26202 
David, M., \& Samuel, H. (2014). The role of agriculture extension in the 21st century: Reflections from Africa. International Journal of Agricultural Extension, 2(1), 89-93. https://journals.esciencepress.net/index.php/IJAE/article/view/658/324

Elliot, A. C. (1989). A framework for the evaluation of the capacity-building components in rural development projects: implications to program development and agricultural extension education. Retrospective Theses and Dissertations. https://doi.org/10.31274/rtd180813-8970

Food and Agricultural Organization of the United Nations. (2019). Haiti / humanitarian response plan 2019-2020. http://www.fao.org/3/CA3258EN/ca3258en.pdf

Food and Agricultural Organization of the United Nations \& World Food Programme. (2020). Monitoring food security in countries with conflict situations. A joint FAO/WFP update for the members of the United Nations Security Council. https://www.wfp.org/publications/monitoring-food-security-countries-conflictsituations

Hall, A., Janssen, W.G., Pehu, E., Rajalahti, R. (2006). Enhancing agricultural innovation: how to go beyond the strengthening of research systems (English). World Bank Group. http://documents.worldbank.org/curated/en/492901468197385434/Enhancingagricultural-innovation-how-to-go-beyond-the-strengthening-of-research-systems

Gibbs, G. (2007). The Sage qualitative research kit, vol. 8: Analyzing qualitative data. Sage.

Gill, T., Ricciardi, V., Bates, R., \& James, D. (2017). Capacity development in agricultural education and training in Cambodia: A SWOT analysis. Journal of International Agricultural and Extension Education, 24(1), 34-50. https://doi.org/10.5191/jiaee.2017.24105

Goertz, H. (2016). Haiti: Landscape analysis. Global Forum for Rural Advisory Services. https://www.g-fras.org/en/component/phocadownload/category/93-reviews-andassessments.html?download=810:haiti-landscape-analysis

Government of Haiti (GoH) (2010). Action plan for national recovery and development of Haiti. GoH. https://whc.unesco.org/document/106589

Hwang, A. S. (1996). Positivist and constructivist persuasions in instructional development. Instructional Science: An International Journal of Learning and Cognition, 24(5), 343356. https://doi.org/10.1007/bf00118112 
Ika, L. A., \& Donnelly, J. (2017). Success conditions for international development capacity building projects. International Journal of Project Management, 35(1), 44-63. https://doi.org/10.1016/j.ijproman.2016.10.005

Kraak, A., Paterson, A., Boka, K., Papier, J., Needham, S., Prinsloo, N., \& McBride, T. (2016). Preparing TVET college graduates for the workplace employer' views. In Change Management in TVET Colleges: Lessons Learnt From the Field of Practice (pp. 83-102). African Minds.

Leischow, S. J., \& Milstein, B. (2006). Systems thinking and modeling for public health practice. American Journal of Public Health, 96(3), 403-405. https://doi.org/10.2105/AJPH.2005.082842

Lincoln, Y. G., \& Guba, E. (1985). Naturalistic inquiry. Sage Publications.

Merriam, S. B. (1998). Qualitative research and case study applications in education. JosseyBass Publishers.

Mcquaid, R. W., \& Lindsay, C. (2005). The concept of employability. Urban Studies, 42(2), 197219. https://doi.org/10.1080/0042098042000316100

Mouzakitis, G. S. (2010). The role of vocational education and training curricula in economic development. Procedia Social and Behavioral Sciences, 2, 3914-3920. https://doi.org/10.1016/j.sbspro.2010.03.616

Organisation for Economic Co-operation and Development (OECD). (2012). Supporting partners to develop their capacity: Twelve lessons from DAC peer reviews. http://www.oecd.org/dac/peer-reviews/12lessonscapdev.pdf

Pierre, A., Calixte, M. C., Moore, K., Bunch, J. C., Koenig, R., Delva, L., \& Roberts, T. G. (2018). Haitian agricultural faculty preparation for their academic roles. Journal of International Agricultural and Extension Education, 25(1), 24-38. https://doi.org/10.5191/jiaee.2018.25103

Pierre, A., Calixte, M. C., Moore, K., Bunch, J. C., \& Roberts, T. G. (2018). Haitian faculty perceptions of students' competence at graduation: An opportunity for curricula modification. Journal of International Agricultural and Extension Education, 25(3), 2032. https://doi.org/10.5191/jiaee.2018.25302

Riebe, L., Girardi, A., \& Whitsed, C. (2016). A systematic literature review of teamwork pedagogy in higher education. Small Group Research, 47(6), 619-664. https://doi.org/10.1177/1046496416665221 
Rivera-Ferre, M., Ortega-Cerdà, M., \& Baumgärtner, J. (2013). Rethinking study and management of agricultural systems for policy design. Sustainability, 5(9), 3858-3875. https://doi.org/10.3390/su5093858

Senge, P. (1990). The fifth discipline, the art and practice of the learning organization. Doubleday/Currency.

The United Nations Educational, Scientific and Cultural Organization. (2015). UNESCO TVET strategy 2016-2021: Report of the UNESCO-UNEVOC virtual conference. http://unesdoc.unesco.org/images/0024/002439/243932e.pdf

Yilmaz, K. (2008). Constructivism: Its theoretical underpinnings, variations, and implications for classroom instruction. Educational Horizons, 86(3), 161-172. www.jstor.org/stable/42923724

(C) 2020 by authors. This article is an open access article distributed under the terms and conditions of the Creative Commons Attribution license (http://creativecommons.org/licenses/by/4.0/). 